\title{
Isothermal microcalorimetry for thermal viable count of microorganisms in pure cultures and stabilized formulations
}

\author{
Johanna Nykyri ${ }^{1}$, Anke M. Herrmann² and Sebastian Håkansson ${ }^{1 *}$
}

\begin{abstract}
Background: Quantification of viable microorganisms is an important step in microbiological research as well as in microbial product formulation to develop biological control products or probiotics. Often, the efficiency of the resulting product is dependent on the microbial cell density and their viability, which may decrease over time. Commonly, the number of viable cells is determined by serial dilution and plating techniques or flow cytometry. In 2017, we developed a mathematical model for isothermal microcalorimetry (IMC) data analysis and showed that the new method allows for a more rapid quantification of viable fresh and freeze-dried anaerobic Lactobacillus reuteri cells than traditional viable count methods.

Results: This study developed the new method further by applying it to well-known aerophilic plant-beneficial microbial species (Pseudomonas brassicacearum, Bacillus amyloliquefaciens subsp. plantarum and Clonostachys rosea) used in biological control products. We utilized IMC to quantify viable cells in microbial pure cultures as well as when coated onto wheat seeds. The results from this study confirmed that thermal viable count methods are more rapid and sensitive than traditional viable count techniques. Most interestingly, a thermal viable count method was able to quantify microbes coated on seeds despite the presence of the natural microbiota of the seeds. Our results also showed that, in contrast to plating techniques for which clustered cells skew the results, IMC does not require single cells for accurate viable counts.

Conclusions: Thermal viable count methods are novel methods for the rapid quantification of divergent bacterial and fungal species and enhance the speed, sensitivity, and accuracy of routine viable counts of pure cultures and controlled microbiomes such as plant seed coatings.
\end{abstract}

Keywords: Viable count, Isothermal microcalorimetry, Aerophilic, Microbial products, Plant seed coating, Biological control, Plant protection

\section{Background}

Microbes are present in all kinds of environments, both natural and man-made, and they are utilized in multiple industrial processes or products. When considering microbial applications, it is of utmost interest whether the microbes are viable and how to best quantify them [1-4]. For example, in the case of microbial plant protection products [1] or probiotics [3], viable cell concentrations have dramatic effects on the efficacy of the products when they are applied. In certain products, such as coated seeds, the

\footnotetext{
* Correspondence: sebastian.hakansson@slu.se

'Department of Molecular Sciences, Swedish University of Agricultural

Sciences, P.O. Box 7015, SE-75007 Uppsala, Sweden

Full list of author information is available at the end of the article
}

natural microbiota generate background in viable count processes. The stability of products and long shelf lives are of interest for the entire supply chain, from manufacturers to end-users. To reach these goals more efficiently, new rapid and accurate quality control systems for viable counts or viability assessments would be an advantage.

Currently, viability assessments or viable counts of microbes rely mainly on dilution series and plating techniques, flow cytometry and different microscopy techniques $[1,2,4]$. The method of serial dilutions and plating is still considered the gold standard. The results of flow cytometry and microscopy techniques are often difficult to interpret because cells could respond oddly to the staining process, giving false positives and negatives [1-3].

(c) The Author(s). 2019 Open Access This article is distributed under the terms of the Creative Commons Attribution 4.0 International License (http://creativecommons.org/licenses/by/4.0/), which permits unrestricted use, distribution, and 
However, serial dilutions and plating techniques also have limitations: (i) They require a relatively long time span (up to several days) to obtain results; (ii) the microbes need to be cultivable, but $99 \%$ of microbes are non-cultivable; (iii) these techniques have poor automation possibilities; and (iv) they do not differentiate whether cells are single or attached together to form a larger unit, thus underestimating the viable count [1-3]. Nucleic acid-based methods, such as quantitative PCR, have been routinely used to quantify and identify microbes. However, these methods do not generally differentiate whether microbes are viable or not, despite the efforts to develop these methods towards viable counting [1-3].

In addition to these traditional methods, isothermal microcalorimetry (IMC) has been proposed to have potential in viable count or viability assessment $[1,2,5,6]$. IMC measures the amount of heat released from a sample by any physical, biological or chemical process [6]. In microbiology and related fields, IMC has been commonly applied in clinical applications to detect infection or to diagnose diseases, and in environmental sciences, IMC is used to measure metabolic activity in different types of soil samples [6]. The vast majority of IMC applications have utilized IMC methodology for purposes other than quantitative or viable counting. However, IMC has been utilized to estimate soil microbial biomass relative to its microbial activity, focusing on general microbial activity in divergent soils and the carbon cycle for land management [7-10].

A few articles describe findings that have paved the way for fine-tuned quantification of viable microbial cells by IMC. In 2002, Critter and colleagues [11] showed the correlation between viable bacterial and fungal counts and IMC-measured heat production. Bonkat and colleagues in 2012 [12] showed for the first time that there is a link between growth rate and IMC-measured cumulative heat and applied the method to successfully detect common facultative anaerobic urinary tract pathogens in urine. Maskow and colleagues in 2012 [13] took the analysis a step further by presenting a theoretical model to calculate detection times for visual and IMC-based detection of a population originating from a single bacterial cell. They tested the theory by applying it to aerobically and anaerobically growing Escherichia coli and aerobically growing Pseudomonas putida, finding that the time when the microbial heat production was detected by IMC was a function of initial cell density. They also showed how the volume of air in a closed IMC vial should be considered in future applications. Isothermal titration calorimetry has also been used to study the life cycle of Rhodobacter sphaeroides [14], and that study in 2013 found a correlation between cell concentration at log phase and the measured thermal power value.
In 2017, we proposed a novel IMC viability assessment method, from sample preparation to statistical analysis, to quantify viable bacterial cells based on the thermal power detection time point for certain cell concentrations of an initial cell batch [15]. This novel method developed further the earlier calculations of relations between microbial growth and the thermal power [12, 13]. We applied this novel method to quantify viable formulated and freeze-dried microbes; specifically, we utilized IMC to quantify viable fresh as well as formulated and freeze-dried anaerobic gram-positive Lactobacillus reuteri cells [15].

In the current work, our aims were to validate the mathematical model of IMC viability assessment methods [15] and to develop methodology further to quantify a gram-negative bacterium (Pseudomonas brassicacearum), gram-positive bacterium (Bacillus amyloliquefaciens subsp. plantarum) and fungus (Clonostachys rosea) in pure cultures or coated on seeds. We also re-named these methods "thermal viable count methods" to be more precise. These aerophilic plant beneficial microbes are used as biocontrol agents in microbial plant protection products. First, we show how the headspace air volume above culturing media in IMC vials affects the growth of these microbes. Then, we display how initial cell densities affects the detection time of these different microbes by IMC and how thermal viable count methods are applied. Finally, we discuss how the IMC thermal power detection time point is a valid parameter to generate standard curves in thermal viable count methods. To our knowledge, this is the first time that thermal viable count methods are applied to these bacterial and fungal species and the corresponding standard curves are generated; most importantly, it is the first time that they are applied to bacteria coated onto seeds or, generally, to any system other than a pure microbial culture.

\section{Results \\ Headspace air volume in IMC vials affects the microbial thermal power and final cell density}

To find a protocol to utilize IMC to study aerophilic microbial strains, we first investigated the effect of standard IMC running conditions on microbial growth and thermal power. Standard running conditions in IMC may create an environment where the gas exchange is limited and therefore limits the growth of aerophilic microbes. We measured the thermal power $(\mu \mathrm{W})$ of P. brassicacearum MA250, B. amyloliquefaciens subsp. plantarum UCMB5113 and C. rosea IK726 in different volumes (3 $\mathrm{ml}, 6 \mathrm{ml}, 12 \mathrm{ml}$ and $18 \mathrm{ml}$ ) of culturing media (tryptic soy broth (TSB), Luria broth (LB), or potato dextrose broth (PDB), respectively) in $20 \mathrm{ml}$ vials. Different volumes of media created different ratios of culturing 
media volume to headspace air volume in the capped vials. All the tested microbial strains gave their strongest thermal power output and grew to their highest densities $(\mathrm{cfu} / \mathrm{ml})$ or greatest biomass $(\mathrm{mg} / \mathrm{ml})$ when there was a $3 \mathrm{ml}$ or $6 \mathrm{ml}$ culture in an IMC vial (Fig. 1a, b, and c, Additional file 1). There were no statistically significant differences between the properties of $3 \mathrm{ml}$ and $6 \mathrm{ml}$ cultures for each microbial strain. When we increased the culturing volume to $12 \mathrm{ml}$, the thermal power output and cell concentration or biomass were lower for Pseudomonas $(p<0.01)$ and Clonostachys $(p<0.01)$ than they were in cultures of $3 \mathrm{ml}$ and $6 \mathrm{ml}$ (Fig. 1a and c, Additional file 1). When we increased the culturing volume to $18 \mathrm{ml}$, the thermal power output and cell concentration or biomass were considerably lower in all of the studied strains $(p<0.01)$ than they were in cultures of $3 \mathrm{ml}, 6 \mathrm{ml}$ and $12 \mathrm{ml}$ (Fig. 1a, b, and c, Additional file 1). In conclusion, the culturing volumes had an effect on the thermal power curves and cell density, and in larger volumes, the cultures reached stationary phase earlier.

\section{Thermal viable count methods are able to quantify} microbes in pure cultures and coated on seeds

To study if IMC could be used to quantify viable microbial cells, we studied dilution series of $P$. brassicacearum MA250, B. amyloliquefaciens subsp. plantarum UCMB5113 spores and $C$. rosea IK726 conidia by measuring the thermal power $(\mu \mathrm{W})$ of each dilution by IMC. Based on the results with pure cultures, we decided to prepare a dilution series of $P$. brassicacearum MA250 coated onto wheat seeds and measure the thermal power $(\mu \mathrm{W})$ of coated seed batches by IMC. IMC was able to differentiate initial cell densities of $P$. brassicacearum MA250 in pure cultures with a resolution as low as $\sim 0.2-0.4 \log (\mathrm{cfu} / \mathrm{ml})$ (Figs. 2). However, in the case of $P$. brassicacearum MA250-coated seeds, IMC differentiated initial microbial cell densities with a resolution from $\sim 0.5-1 \log$ (cfu/g seed) (Figs. 2b and $3 \mathrm{~b}$ and c). IMC differentiated pure cultured $B$. amyloliquefaciens subsp. plantarum UCMB5113 initial cell densities with an $\sim 0.6-0.8 \log$ (cfu/ml) resolution and C. rosea IK726 with an $\sim 1-1.5 \log$ (cfu/ml) resolution (Figs. 2c and d and 3d and e). Regression analyses showed that the model fits the data well $\left(R^{2}=\right.$
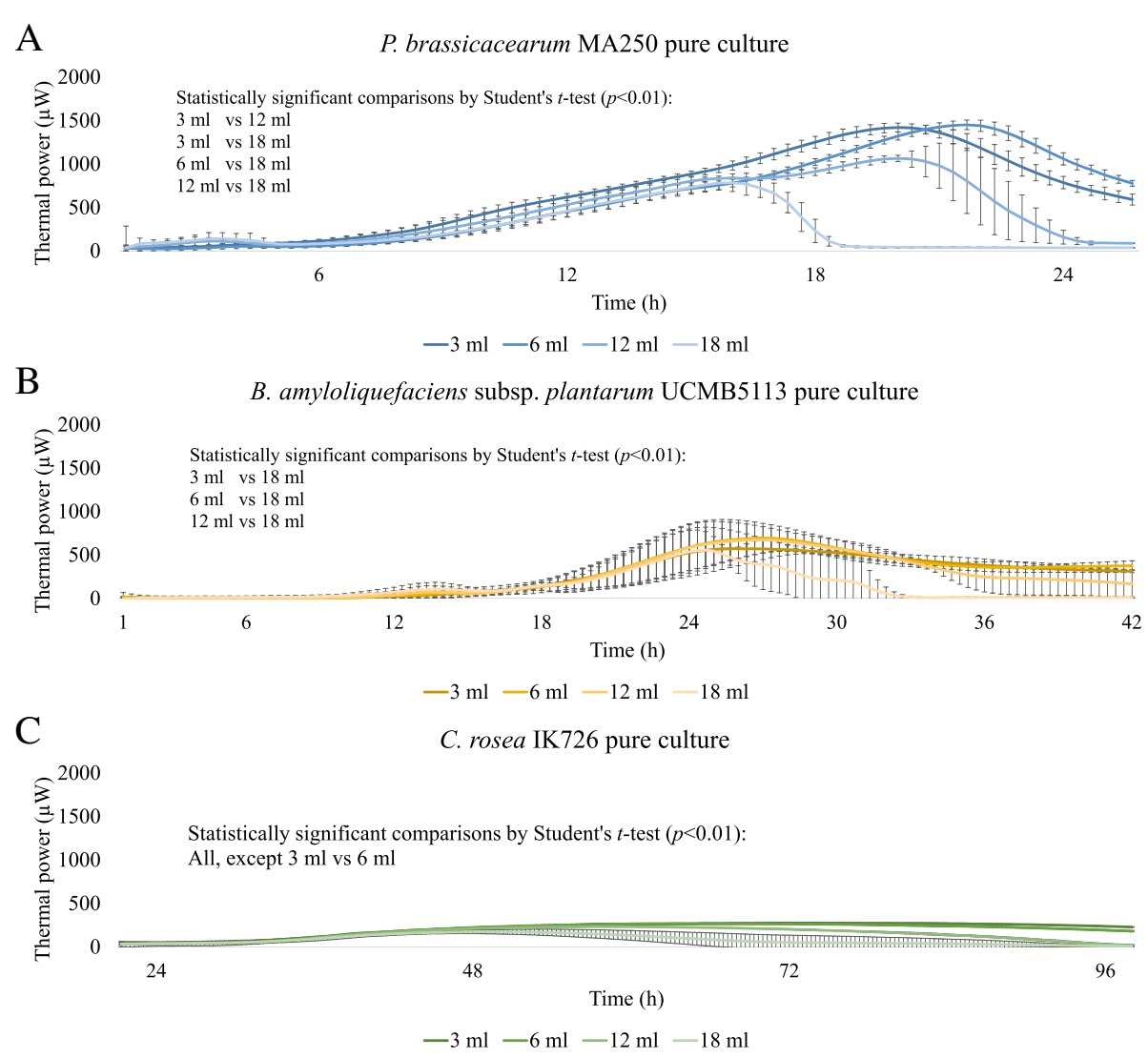

Fig. 1 Isothermal microcalorimetry thermal power $(\mu \mathrm{W})$ curves of microbes in different culturing volumes $(3,6,12$ and $18 \mathrm{ml})$. a Pseudomonas brassicacearum MA250 in TSB, $25^{\circ} \mathrm{C}$. b Bacillus amyloliquefaciens subsp. plantarum UCMB5113 in LB, $25^{\circ} \mathrm{C}$. c Clonostachys rosea IK726 in PDB, $25^{\circ} \mathrm{C}$. The figures for Pseudomonas and Bacillus represent the averages and standard deviations of three independent experiments with 3-6 replicates per treatment. The figure for C. rosea IK726 represents the averages and standard deviations of six replicates per treatment 

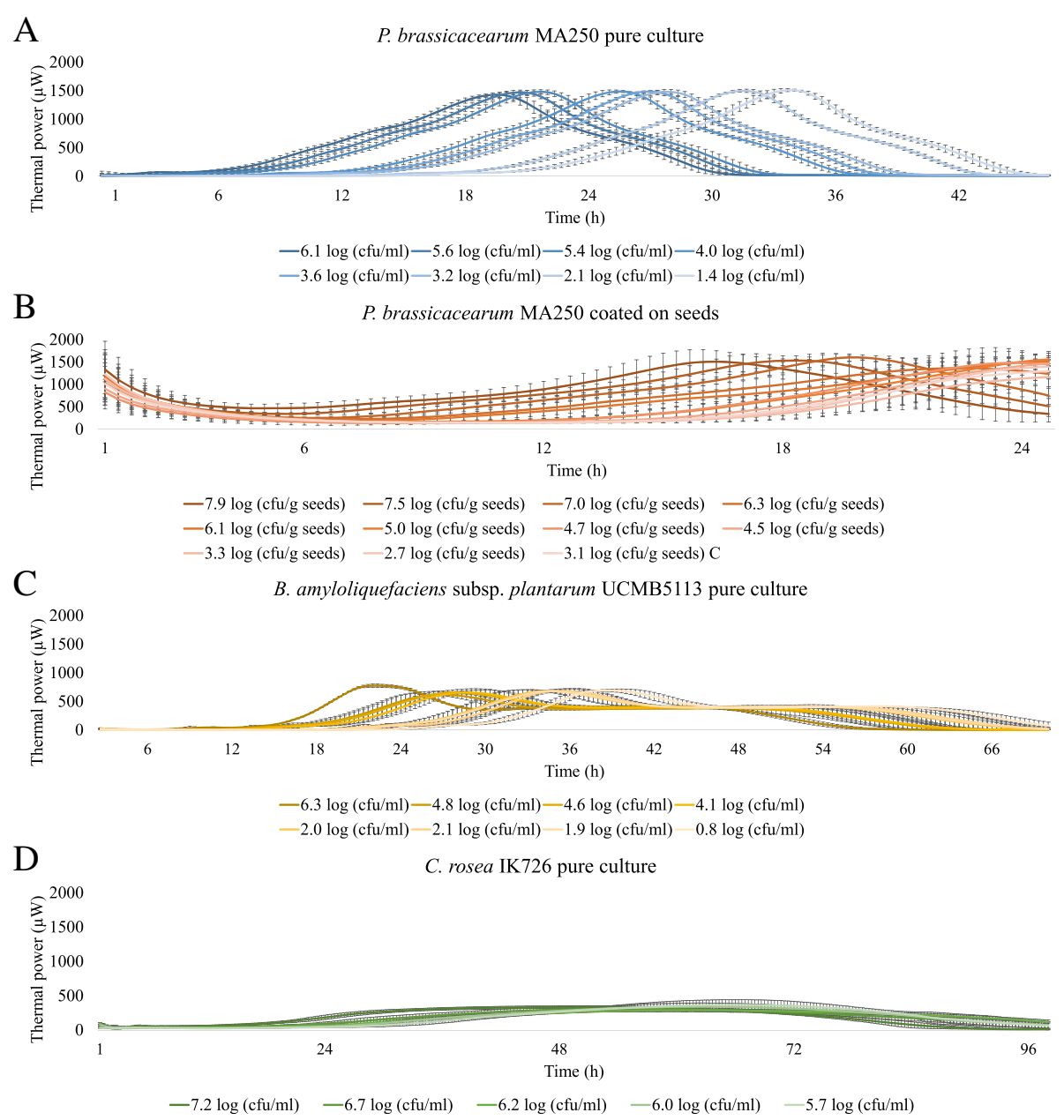

Fig. 2 Isothermal microcalorimetry thermal power curves $(\mu \mathrm{W})$ and respective initial microbial cell densities for each curve (log (cfu/ml)). The pure culture volume was $6 \mathrm{ml}$, and the seed sample size was $3 \mathrm{~g}$, supplemented with $5.5 \mathrm{ml}$ of media. a Pseudomonas brassicacearum MA250 pure culture in TSB, $25^{\circ} \mathrm{C}$. b $P$. brassicacearum MA250 coated on wheat seeds, $25^{\circ} \mathrm{C}$. C = surface sterilization control ( $3.1 \log$ (cfu/ml)). c Bacillus amyloliquefaciens subsp. plantarum UCMB5113 in LB, $25^{\circ} \mathrm{C}$. d Clonostachys rosea IK726 in PDB, $25^{\circ} \mathrm{C}$. Each strain displayed distinct and repeatable thermal power curves. The figures represent the averages and standard deviations of 2-3 independent experiments with 3-6 replicates each

0.91-1.00) when detection times were compared at certain thermal power values and cell concentrations (Fig. 3, Table 1).

Interestingly, the seed surface sterilization control carrying residual natural microbiota, fitted in the same standard curve as samples with coated seeds when a regression analysis was made with both data sets (Fig. 3b, surface sterilization control is marked with an arrow in the figure). Based on serial dilutions and plating, the density of the natural microbiota on wheat seeds was approximately 2-3 $\log$ (cfu/g seed) after surface sterilization. To study if the model also fits the data collected from $P$. brassicacearum MA250 pure cultures and coated seeds, we fitted the time point data collected from both treatments' thermal power values of $500 \mu \mathrm{W}$ and $800 \mu \mathrm{W}$ in the same standard curve generated by a regression analysis. To minimize the possible effect of the seeds' natural microbiota on the quantification of MA250, we excluded data from surface sterilization controls and samples with the lowest MA250 cell density $(<5 \mathrm{log})$. The model fitted the data collected from P. brassicacearum MA250 pure cultures and coated seeds combined together well (Fig. 3c, Table 1). Therefore, these data of pure cultures and coated seeds support the correlation between the detection time point and cell concentration at a specific IMC thermal power value.

The natural microbiota of seeds affects the thermal viable count method at low cell densities of coating

The natural microbiota of wheat seeds affected the quantification of P. brassicacearum MA250 on seeds when the initial MA250 cell concentration on seeds was below $\sim 5 \log$ (cfu/g seed), which was reflected by the increased variances in log (cfu/g seeds) in different experiments (Figs. 2b and 3b). P. brassicacearum MA250-specific 


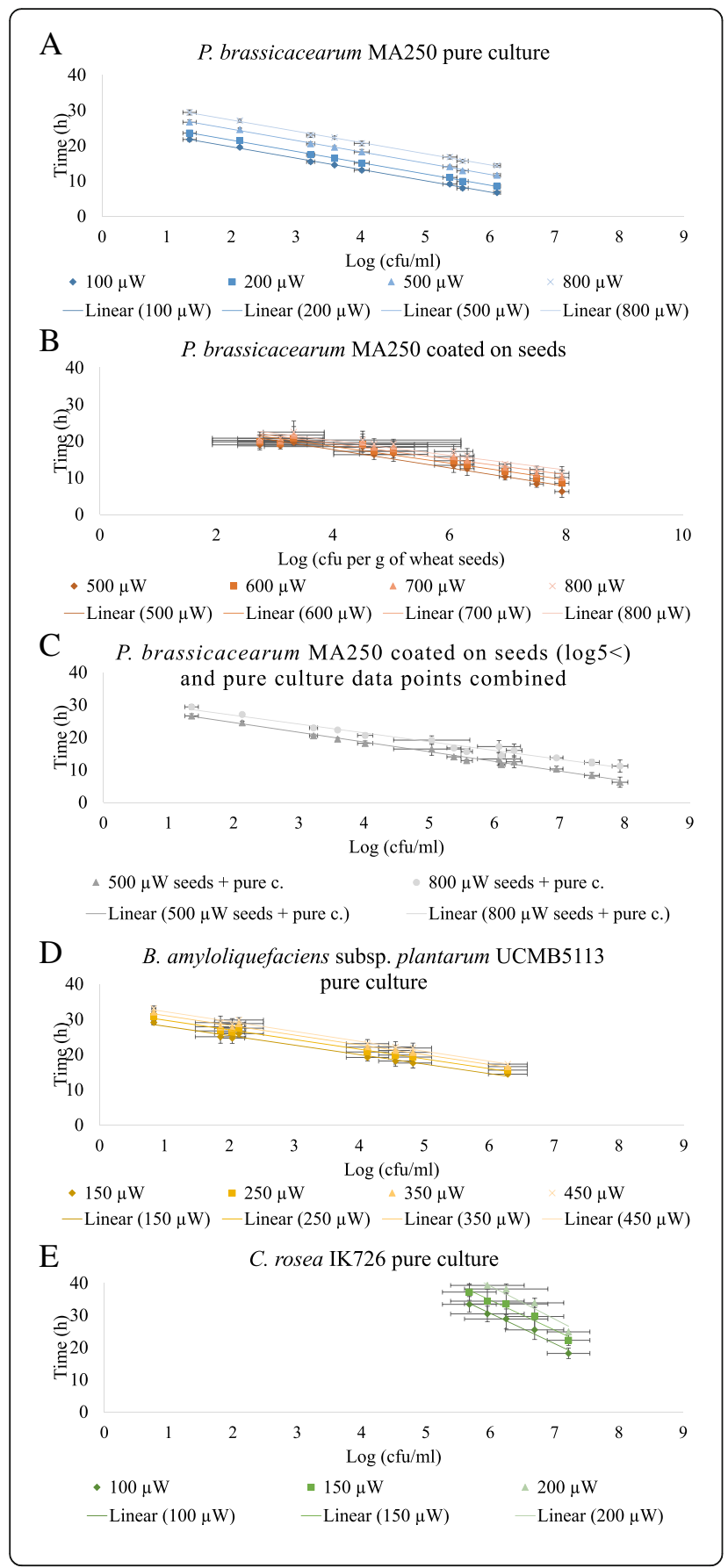

Fig. 3 Regression analyses of cell concentrations (log $(\mathrm{cfu} / \mathrm{mll}))$ and detection times $(h)$ at certain thermal power values to determine the correlation and resolution of isothermal microcalorimetry thermal power curves for the quantification of microbial densities. a The Pseudomonas brassicacearum MA250 resolution in pure culture was 0.2-0.4 log (cfu/ $\mathrm{ml})$. b The $P$. brassicacearum MA250 resolution after seed coating was 0.5-1 log (cfu/g seed). c Different thermal power (500 $\mu \mathrm{W}$ and $800 \mu \mathrm{W}$ ) time points of $P$. brassicacearum MA250 pure cultured samples and coated seed samples fitted into the same regression curve despite of the differences in the resolution per treatment (see Fig. $3 a$ and b). $\mathbf{d}$ The Bacillus amyloliquefaciens subsp. plantarum UCMB5113 strain's resolution in pure culture was $\sim 0.6-0.8 \mathrm{log}(\mathrm{cfu} / \mathrm{ml})$. e The Clonostachys rosea IK726 resolution in pure culture was $\sim 1-1.5 \mathrm{log}(\mathrm{cfu} / \mathrm{ml})$. The figures represent the averages and standard deviations of 2-3 independent experiments with 3-6 replicates each

sequence characterized amplified region polymerase chain reaction (SCAR-PCR) primers and 16S rRNA gene sequencing detected the presence of the said strain on wheat seeds at the beginning and at the end of IMC measurements. During the experiments, colony morphology and $16 \mathrm{~S}$ rRNA gene sequencing were utilized to determine what microbial species were present on coated and surface-sterilized seeds (Additional file 2). The reciprocal best hits by BLASTN suggested that we found other Pseudomonas strains and Pantoea and Paenibacillus strains in samples just before and after IMC runs (Additional file 3). The natural microbiota of wheat seeds was detected mainly in samples whose seed coating cell density was low or in the surface sterilization controls, where the seeds were only surface-sterilized and not coated.

\section{Discussion}

The viable count of microbes is commonly calculated by serial dilution and plating techniques, which are the gold standard [1,3]. In a previous study [15], we showed how an thermal viable count method is competitive with flow cytometry due to the reliability of IMC and showed that IMC is a faster tool for quantifying anaerobic $L$. reuteri than serial dilutions and plating. Other studies have noted that IMC is a sensitive method that detects the presence of microbes earlier than most known growth or viability measuring methods [5]. In this work, we have shown that thermal viable count methods are also faster methods to quantify aerophilic bacteria and fungi than serial dilutions and plating. To obtain countable colonies by serial dilutions and plating, researchers may have to wait 24-48 h with Pseudomonas and Bacillus, over $48 \mathrm{~h}$ with Clonostachys and, generally, 1-7 days, depending on the microbial strain. After $1-2 \mathrm{~h}$ of preparations in the thermal viable count methods, a wide variety of cell concentrations of pure cultured Pseudomonas was detected within 6-21 h, of Bacillus within 18-28 h and of Clonostachys within 18$32 \mathrm{~h}$ (Figs. 2 and 3). Notably, we also quantified viable Pseudomonas cells coated on wheat seeds after 6-11 h 
Table 1 Detection time equations for the relationships between initial microbial cell densities (log (cfu/ml)) and detection times (isothermal microcalorimetry thermal power values) for strains Pseudomonas brassicacearum MA250, Bacillus amyloliquefaciens subsp. plantarum UCMB5113 and Clonostachys rosea IK726. In all strains, initial cell densities correlated with thermal power values. The results represent the averages of $2-4$ independent experiments

\begin{tabular}{|c|c|c|c|}
\hline Strain and culturing conditions & Thermal power $(\mu \mathrm{W})$ & Detection Time Equation (h) & $R^{2}$ \\
\hline \multirow[t]{4}{*}{ P. brassicacearum MA250 pure culture } & 800 & $-3.12 x+33.49$ & 1.00 \\
\hline & 500 & $-3.15 x+31.02$ & 1.00 \\
\hline & 200 & $-3.12 x+27.86$ & 1.00 \\
\hline & 100 & $-3.16 x+26.06$ & 1.00 \\
\hline \multirow[t]{4}{*}{ P. brassicacearum MA250 coated on seeds } & 800 & $-2.01 x+28.16$ & 0.91 \\
\hline & 700 & $-2.12 x+27.83$ & 0.92 \\
\hline & 600 & $-2.28 x+27.71$ & 0.94 \\
\hline & 500 & $-2.50 x+27.69$ & 0.93 \\
\hline \multirow{2}{*}{$\begin{array}{l}\text { P. brassicacearum MA250 Seeds } 5<\log \text { (cfu/g seeds) } \\
+ \text { pure culture combined data }\end{array}$} & 800 & $-2.71 x+32.26$ & 0.97 \\
\hline & 500 & $-2.99 x+30.55$ & 0.99 \\
\hline \multirow{4}{*}{$\begin{array}{l}\text { B. amyloliquefaciens subsp. plantarum UCMB5113 } \\
\text { pure culture }\end{array}$} & 450 & $-2.81 x+35.01$ & 0.99 \\
\hline & 350 & $-2.78 x+33.88$ & 0.99 \\
\hline & 250 & $-2.75 x+32.53$ & 0.99 \\
\hline & 150 & $-2.69 x+30.76$ & 0.98 \\
\hline \multirow[t]{3}{*}{ C. rosea IK726 pure culture } & 200 & $-10.28 x+100.80$ & 0.93 \\
\hline & 150 & $-9.29 x+90.49$ & 0.96 \\
\hline & 100 & $-9.41 x+87.13$ & 0.97 \\
\hline
\end{tabular}

and generated a standard curve despite the residual natural microbiota present after the surface sterilization and coating of the wheat seeds, which may skew the viable count results (Figs. 2 and 3). The natural microbiota was approximately 2-3 log (cfu/g seed), causing increased variance when the cell density of the coated Pseudomonas decreased below five log (cfu/g seed) (Figs. 2 and 3). However, the model fitted the data well, even when the population was a mixture of coated microbial cells and the residual natural microbiota of the wheat seeds. That the model fitted in all cases could be explained by the fact that the majority of the microbes found from the samples were other Pseudomonas (Additional file 3) or had otherwise similar features, thus producing similar thermal power profiles under the conditions used. The data validated our previously justified model for the thermal viable count method (viability assessment) of $L$. reuteri [15]. Using the detection time of certain thermal power values for each initial microbial cell density is, indeed, a suitable method to apply to cases other than the specific $L$. reuteri model.

The resolution or ability of the thermal viable count methods to differentiate cell densities varied with microbial genus and culturing conditions (Figs. 2 and 3). The obtained resolution ( $\sim 2-10$-fold changes) of the utilized methods for viable counting is sufficient for most microbiological applications. Pseudomonas showed as accurate a resolution as L. reuteri in our previous work [15], but
Bacillus and Clonostachys showed more variation between experiments. However, we should emphasize that these standard curves were built based on three independent experiments and that each experiment had slightly different initial cell densities, which contributed to the variance in the standard curves. Therefore, we suggest having better control of the variance of the initial cell density when standard curves of greater accuracy are required.

In addition to other growth requirements, the availability of air should be taken into account when studying aerophilic microbes by IMC [13]. The aerophilic microbial strains in this study have different growth requirements than the anaerobic microbe $L$. reuteri, the subject of our previous study [15-20]. Our results (Fig. 1) showed that the ratio of culturing medium volume to headspace air volume in IMC vials has an effect on the microbial growth during IMC analyses and that this ratio should be considered when planning further IMC experiments.

IMC is known to be a non-specific method that measures all heat produced or consumed in samples $[2,5,6]$. In this work, the surface sterilization of seeds and the culturing conditions in IMC vials could have enriched the $P$. brassicacearum MA250 in the coating as well as certain genera of that natural microbiota that were found, namely, Pseudomonas, Pantoea, and Paenibacillus (Additional file 3). These genera are commonly found in wheat seeds [21, 22]. 
However, the natural microbiota of wheat seeds could be much more diverse [21-24]. When studying seed coatings, it could also be important to take into account possible seed germination, the heat flow it produces, and its effect on IMC measurements. In this work, we prevented seed germination by immersing the seeds in culturing media. This is most likely explained by the fact that the salinity of media lowered the water potential inhibiting germination. In conclusion, we propose that the specificity of thermal viable count methods could be enhanced by specific sample preparation protocols and using culturing media or substrates enriching the species of interest if the sample is composed of different organisms.

The accuracy of IMC is not dependent on single cells due to its non-specific nature. Our model strains grow differently in pure cultures or if they are coated on seeds, and the thermal viable count methods were applicable in all cases (Fig. 2). In the case of Pseudomonas, we did not detect any specific additional grouping of cells within IMC vials (Additional file 4: Figure S1 and S2). Bacillus species generate cell chains and grow in clusters in liquid media when not shaken $[18,25]$. The Bacillus strain in the current study behaved similarly in IMC vials, producing rafts near the medium surface and keeping most of the media clear (Additional file 4: Figure S3). Clonostachys grows abundant mycelia and, in some conditions, conidia [19]. In the current study, the Clonostachys strain grew a thick layer of hyphae near the medium surface, but no conidium formation was detected under these conditions (Additional file 4: Figure S4). Viable counting of biofilms or biofilm-like structures often requires enhanced protocols, including the disruption of biofilm to utilize dilution series and plating techniques or flow cytometry [26]. IMC has been applied to study biofilms with increasing frequency during the past few years but has not actually been applied to quantify viable cells [27-30]. Therefore, based on our results demonstrating the versatile ability of IMC to quantify the initial viable count of differentially growing microbes, we propose that IMC also has potential to quantify microbes within biofilms and may even quantify selected species within biofilms, similar to the coatings on wheat seeds in this study. However, it should be considered whether a medium, substrate, or species-specific standard curve corresponding to the system of interest should be established.

Thus far, we have discussed the speed, sensitivity and accuracy of IMC measurements as well as how to enhance the specificity of thermal viable count methods. In addition, IMC results can also be followed in real time, IMC-based methods do not require stains or toxic or isotope-labelled chemicals, and downstream applications are optional, similar to standard microbial cultures $[2,5,6]$. Today, high-throughput workflows are becoming mainstream in many biological fields due to the possibility to work, for example, with metagenomics or in a 384-well format with robotics during sample preparation and measurements. We consider the good possibilities to automate the sample preparation process, and IMC equipment is being developed in high-throughput configurations. To our knowledge, a 48-channel system is currently the largest single instrument available for IMC (TA Instruments).

Herein and in our previous work [15], we have proposed and applied a method, thermal viable count, for analysing IMC data and supported it with a workflow for sample preparation and IMC measurements. Thermal viable count methods might overcome and benefit from previously noted challenges related to the non-specificity of IMC measurements [2, 5, 6]. After the preparation of standard curves, the use of IMC equipment and comparison of IMC results to the standard curves would be fast and not require more than standard laboratory skills and brief training. In the simplest IMC procedure, a researcher could add a product or sample of interest into an IMC vial and supplement it with a sufficient amount of substrate to enrich or activate a microbial species of interest. Then, the thermal power produced by IMC would be measured, and the detection time $(t)$ of certain thermal power value $(\mu \mathrm{W})$ would be noted; these results would be compared to a pre-prepared standard curve to approximate the concentration of viable cells in the sample. Therefore, we propose that these methods could be easily transformed into standard procedures in industry and research and official control laboratories. In future studies, generalized standard curves applicable to different microbial groups or substrates may be developed and commonly available.

\section{Conclusions}

Isothermal microcalorimetry based thermal viable count methods are promising novel methods for the rapid quantification of divergent bacterial and fungal species to enhance routine viable counting processes in academia, industry, and control authorities.

\section{Methods}

\section{Strains and culturing conditions}

Pseudomonas brassicacearum MA250 [16], Bacillus amyloliquefaciens subsp. plantarum UCMB5113 [17, 18], and Clonostachys rosea IK726 [19] were used in this study. P. brassicacearum MA250 cells were cultured in tryptic soy broth (TSB) $(105,459$, Merck, Germany) with shaking at $210 \mathrm{rpm}$ or on TSA (TSB + agar) $(105,458$, Merck, Germany) at $25^{\circ} \mathrm{C}$. B. amyloliquefaciens subsp. plantarum UCMB5113 cells were cultured in Luria broth (LB) Miller (L1520, USBiological Life Sciences, USA) with $210 \mathrm{rpm}$ shaking or on LB Lennox plates (L2897, Sigma-Aldrich, USA) at $30^{\circ} \mathrm{C}$, but IMC analyses 
were performed at $25^{\circ} \mathrm{C}$. C. rosea $\mathrm{IK} 726$ cells were cultured in potato dextrose broth (PDB) (P6685, Sigma-Aldrich, USA) with $210 \mathrm{rpm}$ shaking or on PDA (PDB + agar) plates $\left(110,130\right.$, Merck, Germany) at $25^{\circ} \mathrm{C}$.

\section{Serial dilutions and plating technique to obtain viable count and biomass measurements}

Serial dilutions and plating technique was performed during the study when needed. Samples were diluted up to a computed $10^{1} \mathrm{cfu} / \mathrm{ml}$ with 10 -fold serial dilutions. From each dilution, 3-8 $\times 10 \mu \mathrm{l}$ drops were placed on LB, TSA or PDA plates. The plates were incubated 1-2 days, and log (cfu/ml) was calculated. The biomass $(\mathrm{mg} / \mathrm{ml})$ of $C$. rosea IK726 mycelia was weighed wet during the study when needed. Mycelia was collected from the culture and briefly dried against a paper towel to remove dripping water.

\section{Collection of endospores and conidia}

B. amyloliquefaciens subsp. plantarum UCMB5113 batches were cultured three days in liquid cultures to collect endospores for the experiments. Cells were heat-treated at $75^{\circ} \mathrm{C}$ for $10 \mathrm{~min}$ to harvest endospores as previously described [31]. The stock concentration of endospores was calculated by serial dilutions and plating viable count analysis. Endospores were stored in $\mathrm{LB}$ at $4{ }^{\circ} \mathrm{C}$ and used within 3 weeks. C. rosea IK726 was grown for 714 days to collect conidia for the experiments. One conidium batch was collected out of four full PDA plates by washing the plates with $25 \mathrm{ml}$ of PDB. Conidia and mycelia were filtered through sterilized cotton plugs to harvest conidia [32]. The final volume of a conidium batch was $20 \mathrm{ml}$. Conidium collection and purity were confirmed by light microscopy (Olympus BH-2, Olympus, Japan) and serial dilutions and plating viable count analysis. Conidium batches were prepared freshly for the experiments.

\section{Isothermal microcalorimetry}

Standard $20 \mathrm{ml}$ IMC vials were capped with matching rubber-metal caps (TA Instruments, USA), and the microbial cultures were cultivated without shaking during analyses. The IMC analyses were performed by an 8-channel TAM Air isothermal microcalorimetry instrument (TA Instruments, USA). Samples were equilibrated $30-60 \mathrm{~min}$ at $25^{\circ} \mathrm{C}$ prior to IMC measurements in capped IMC vials. All IMC measurements were performed at $25^{\circ} \mathrm{C}$. The IMC data were analysed by TAM Air Assistant v.1.4.2.38 (2011) software (TA Instruments, USA). Data points from every 20 min were exported into Excel for statistical analyses and visualization.

\section{Sample preparation for isothermal microcalorimetry with} microbial pure cultures

$P$. brassicacearum MA250 was grown overnight, pelleted, resuspended, and diluted to the desired cell concentration prior to being pipetted into IMC vials. $B$. amyloliquefaciens subsp. plantarum UCMB5113 endospore batches and C. rosea IK726 conidium batches were pelleted, resuspended, and diluted prior to their pipetting into IMC vials. To study the effect of headspace air volume in vials on microbial growth, different volumes $(3 \mathrm{ml}, 6 \mathrm{ml}, 12 \mathrm{ml}$, and $18 \mathrm{ml}$ ) of diluted o/n culture of MA250 $\left(\sim 10^{5} \mathrm{cfu} / \mathrm{ml}\right)$, diluted spores of UCMB5113 ( $\left.10^{6} \mathrm{cfu} / \mathrm{ml}\right)$ or diluted conidia of IK726 $\left(\sim 10^{6} \mathrm{cfu} / \mathrm{ml}\right)$ were pipetted into separate IMC vials $(20 \mathrm{ml})$. To study the effect of different cell concentrations on the detection time of thermal power, $6 \mathrm{ml}$ of 5-8 different dilutions were pipetted into separate IMC vials. The inert control contained $\mathrm{ddH}_{2} \mathrm{O}$, and its volume was the same as the respective sample volume. In individual experiments, initial cell concentration $(\mathrm{cfu} / \mathrm{ml})$ was calculated by serial dilutions and plating viable count from a stock dilution that was divided into IMC vials. The end cell concentration $(\mathrm{cfu} / \mathrm{ml})$ of bacteria was calculated by serial dilutions and plating viable count from 2 to 6 pooled technical replicates. The end biomass $(\mathrm{mg} / \mathrm{ml})$ of fungi was weighed from six individual technical replicates. All experiments were repeated independently a minimum of three times with 3-6 replicates, except that volume analyses of $C$. rosea IK726 were performed once with six replicates and measurements with certain cell concentrations $(6.3,2.1$ and $0.8 \log (\mathrm{cfu} / \mathrm{ml}))$ of B. amyloliquefaciens subsp. plantarum UCMB5113 were repeated twice with 3-6 replicates.

\section{Sample preparation for isothermal microcalorimetry with coated wheat seeds}

Winter wheat (Triticum aestivum L. cv. Norin) seeds (Lantmännen, SE) were coated as previously described [16] with different dilutions $(\mathrm{cfu} / \mathrm{ml})$ of $P$. brassicacearum MA250. Seeds (140 g) were surface-sterilized with $400 \mathrm{ml}$ of $1 / 4$-diluted bleach supplemented with a few drops of Tween 20 for 15 min with occasional mixing and washed six times with the same volume of $\mathrm{ddH}_{2} \mathrm{O}$. The germination rate of seeds at the seed bag was determined by individual samples, which were either non-surface-sterilized, surface-sterilized, or coated. For IMC experiments, coated seeds and seed surface sterilization control seeds were weighed $(3 \mathrm{~g})$ into IMC vials, which were filled up to $8 \mathrm{ml}$ with TSB media (5.5 $\mathrm{ml}$ media). The inert control was $8 \mathrm{ml}$ of $\mathrm{dd}_{2} \mathrm{O}$. The initial cfu of $P$. brassicacearum MA250 per g of seeds was calculated from a sample ( $5.7 \mathrm{~g}$ of seeds, filled up to $14 \mathrm{ml}$ with TSB) taken after the coating process and just before seeds were weighed into IMC vials. This sample was incubated and vortexed a few times during IMC sample preparation $(1-2 \mathrm{~h})$, and then cfu/g seed was counted by serial dilutions and plating viable count. Experiments with coated seeds were repeated independently three 
times with three replicates, except for certain concentrations $(4.5,3.3$ and $2.7 \log (\mathrm{cfu} / \mathrm{ml}))$ whose measurements were repeated independently twice.

\section{Statistical analyses}

To study the linearity of the thermal power detection time point vs cell concentration of the initial cell batch relation at certain thermal power values, regression analyses were performed based on our previously presented mathematical model for this purpose [15]. For regression analyses, thermal power values were chosen based on the individual thermal power curves of each strain. First, a thermal power value was chosen at the point where the IMC measurements were stable and the thermal power curve started to ascend, which was proposed to indicate growth of the bacterial population (Pseudomonas $=100 \mu \mathrm{W}, \quad$ Pseudomonas on wheat seeds = $500 \mu \mathrm{W}$, Bacillus $=150 \mu \mathrm{W}$ and Clonostachys $100 \mu \mathrm{W})$. The last thermal power values were chosen near the peak of the thermal power output, after which the thermal power starts to descend again. When required, statistical analyses were performed by Student's $t$-test for samples with equal variation. All statistical analyses were performed with Microsoft Excel 2016 (Microsoft, USA).

\section{Strain-specific SCAR-PCR to detect Pseudomonas brassicacearum after being coated on wheat seeds}

To confirm the presence of $P$. brassicacearum MA250, we performed MA250 strain-specific SCAR-marker-detecting PCR. Colonies (115 pcs.) were picked from serial dilutions and plating viable count plates before and after IMC experiments for coated and surface-sterilized wheat seeds. Colonies were selected based on their morphology to cover putative MA250 and non-MA250 colonies. Selected colonies represented each independent experiment and seed treatment. Pure cultured MA250 colonies acted as positive controls for SCAR-PCR primers, and E. coli DH5 $\alpha$ acted as negative controls. P. brassicacearum MA250-specific SCAR-PCRs were performed utilizing OPA2-648-forward (TGC CGA GCT GCT AAC CAG ATG CTG G) and OPA2-648-reverse (TGC CGA GCT GAG GGT CGA AGG TCG C) primers [33]. PCRs were run in illustra ${ }^{\text {тм }}$ PuReTaq $^{\text {TM }}$ Ready-To-Go ${ }^{\text {тм }}$ PCR beads (GE Healthcare, UK) supplemented with $1.25 \mu \mathrm{l}$ of each primer $(10 \mathrm{pmol} / \mu \mathrm{l})$ and $22.5 \mu \mathrm{l}$ of sterile $\mathrm{ddH}_{2} \mathrm{O}$. PCRs were run with the following program: $95^{\circ} \mathrm{C} 2 \mathrm{~min}, 30 \mathrm{x}\left(95^{\circ} \mathrm{C} 30 \mathrm{~s}\right.$, $65^{\circ} \mathrm{C} 30 \mathrm{~s}$, and $72^{\circ} \mathrm{C} 30 \mathrm{~s}$ ), and $72{ }^{\circ} \mathrm{C} 5 \mathrm{~min}$. PCR products were analysed by agarose gel electrophoresis.

16S rRNA gene PCR and sequencing to identify members of the microbiota on wheat seeds during experiments

Some of the colonies selected for SCAR-PCR were also selected to confirm their identity via $16 \mathrm{~S}$ rRNA gene PCR. The $16 \mathrm{~S}$ rRNA gene PCRs were also performed for some of the colonies whose morphology indicated that they represent the natural microbiota of wheat seeds. The 16S rRNA gene PCRs were performed utilizing the following primers: 27F AGA GTT TGA TCM TGG CTC AG and 1492R CGG TTA CCT TGT TAC GAC TT [34]. PCRs were run utilizing illustra ${ }^{\mathrm{Tm}}$ PuReTaq $^{\mathrm{Tm}}$ Ready-To-Go ${ }^{\text {тм }}$ PCR beads (GE Healthcare, UK) supplemented with $1.25 \mu \mathrm{l}$ of each primer $(10 \mathrm{pmol} / \mu \mathrm{l})$ and $22.5 \mu \mathrm{l}$ of sterile $\mathrm{ddH}_{2} \mathrm{O}$. PCRs were run with the following program: $95^{\circ} \mathrm{C} 2 \mathrm{~min}, 30 \mathrm{x}\left(95^{\circ} \mathrm{C} 30 \mathrm{~s}, 55^{\circ} \mathrm{C} 30 \mathrm{~s}\right.$ and $72^{\circ} \mathrm{C} 1 \mathrm{~min}$ ), and $72^{\circ} \mathrm{C} 7 \mathrm{~min}$. PCR products were purified utilizing illustra ${ }^{\mathrm{m}}$ GFX PCR DNA and Gel Band Purification Kit (GE Healthcare, UK). PCR products were analysed by agarose gel electrophoresis and sequencing. The $16 \mathrm{~S}$ rRNA gene PCR products of 25 colonies (including one pure cultured MA250 and one E. coli DH5 $\alpha$ ) were submitted for sequencing and sequenced with the same $27 \mathrm{~F}$ and $1492 \mathrm{R}$ primers as PCR (TubeSeq Service, Eurofins Genomics GmbH, DE). Sequencing results were compared to the sequences in the NCBI database by BLASTN suite MegaBLAST to fetch the reciprocal best hits for each colony.

\section{Additional files}

Additional file 1: Table S1. Microbial cell densities before (initial) and after (end) isothermal microcalorimetry measurements. (DOCX 29 kb)

Additional file 2: $16 \mathrm{~S}$ rRNA gene sequences produced in the study in text format. (TXT $49 \mathrm{~kb}$ )

Additional file 3: 165 rRNA gene sequences' BLASTN hits in zipped HTML format. (ZIP $15810 \mathrm{~kb}$ )

Additional file 4: Figure S1. Pseudomonas cultured in IMC vials. Figure S2. Coated seeds in IMC vials. Figure S3. Bacillus cultured in IMC vials. Figure S4. Clonostachys cultured in IMC vials. (DOCX 1472 kb)

\section{Abbreviations}

Cfu: colony-forming unit; IMC: isothermal microcalorimetry; LB: Luria broth; PCR: polymerase chain reaction; PDA: potato dextrose agar; PDB: potato dextrose broth; SCAR: sequence characterized amplified region; TSA: tryptic soy agar; TSB: tryptic soy broth

\section{Acknowledgements}

We thank Professor Johan Meijer for providing us Bacillus amyloliquefaciens subsp. plantarum UCMB5113 and Professor Dan Funck Jensen for Clonostachys rosea IK726. We would also like to thank Armando Hernández Garcia for constructive comments on statistical analyses.

\section{Funding}

This work was funded by the Centre for Biological Control (CBC), the Department of Molecular Sciences and the Faculty of Natural Resources and Agricultural Sciences at the Swedish University of Agricultural Sciences.

\section{Availability of data and materials}

The datasets generated and/or analyzed during the current study is available from the corresponding author on reasonable request.

\section{Authors' contributions}

$\mathrm{SH}$ conceived the original idea. $\mathrm{JN}, \mathrm{SH}$ and $\mathrm{AMH}$ conceived and designed the experiments. JN performed the experiments and analyzed the data. $\mathrm{AMH}$ contributed to IMC equipment. JN and SH wrote the manuscript. All authors read and approved the final manuscript. 


\section{Ethics approval and consent to participate}

Not applicable.

\section{Consent for publication}

Not applicable.

\section{Competing interests}

The authors declare that they have no competing interests.

\section{Publisher's Note}

Springer Nature remains neutral with regard to jurisdictional claims in published maps and institutional affiliations.

\section{Author details}

'Department of Molecular Sciences, Swedish University of Agricultural Sciences, P.O. Box 7015, SE-75007 Uppsala, Sweden. ²Department of Soil and Environment, Swedish University of Agricultural Sciences, P.O. Box 7014 SE-75007 Uppsala, Sweden.

Received: 25 June 2018 Accepted: 6 March 2019

Published online: 21 March 2019

\section{References}

1. Berninger T, González López Ó, Bejarano A, Preininger C, Sessitsch A. Maintenance and assessment of cell viability in formulation of nonsporulating bacterial inoculants. Microb Biotechnol. 2017. https://doi.org/10. 1111/1751-7915.12880.

2. Emerson JB, Adams RI, Román CMB, Brooks B, Coil DA, Dahlhausen K, et al. Schrödinger's microbes: tools for distinguishing the living from the dead in microbial ecosystems. Microbiome. 2017;5:86.

3. Davis C. Enumeration of probiotic strains: review of culture-dependent and alternative techniques to quantify viable bacteria. J Microbiol Methods. 2014;103:9-17.

4. Davey HM. Life, death, and in-between: meanings and methods in microbiology. Appl Environ Microbiol. 2011;77:5571-6.

5. Braissant O, Wirz D, Göpfert B, Daniels AU. Use of isothermal microcalorimetry to monitor microbial activities. FEMS Microbiol Lett. 2010; 303:1-8.

6. Braissant O, Bachmann A, Bonkat G. Microcalorimetric assays for measuring cell growth and metabolic activity: methodology and applications. Methods. 2015;76:27-34

7. Sparling GP. Estimation of microbial biomass and activity in soil using microcalorimetry. J Soil Sci. 2006:34:381-90.

8. Raubuch M, Beese F. Comparison of microbial properties measured by $\mathrm{O} 2$ consumption and microcalorimetry as bioindicators in forest soils. Soil Biol Biochem. 1999;31:949-56.

9. Harris JA, Ritz K, Coucheney E, Grice SM, Lerch TZ, Pawlett M, et al. The thermodynamic efficiency of soil microbial communities subject to longterm stress is lower than those under conventional input regimes. Soil Biol Biochem. 2012;47:149-57.

10. Herrmann AM, Bölscher T. Simultaneous screening of microbial energetics and $\mathrm{CO} 2$ respiration in soil samples from different ecosystems. Soil Biol Biochem. 2015;83:88-92

11. Critter SAM, Freitas SS, Airoldi C. Comparison between microorganism counting and a calorimetric method applied to tropical soils. Thermochim Acta. 2002;394:133-44.

12. Bonkat G, Braissant O, Widmer AF, Frei R, Rieken M, Wyler S, Gasser TC, Wirz D, Daniels AU, Bachmann A. Rapid detection of urinary tract pathogens using microcalorimetry: principle, technique and first results. BJU Int. 2012; 110:892-7.

13. Maskow T, Wolf K, Kunze W, Enders S, Harms H. Rapid analysis of bacterial contamination of tap water using isothermal calorimetry. Thermochim Acta. 2012;543:273-80.

14. Sardaro A, Castagnolo M, Trotta M, Italiano F, Milano F, Cosma P, et al. Isothermal microcalorimetry of the metabolically versatile bacterium <emphasis type="italic" $>$ Rhodobacter sphaeroides</emphasis $>$. J Therm Anal Calorim. 2013;112:505-11.

15. Garcia AH, Herrmann AM, Håkansson S. Isothermal microcalorimetry for rapid viability assessment of freeze-dried Lactobacillus reuteri. Process Biochem. 2017;55(Supplement C):49-54.
16. Levenfors JP, Eberhard TH, Levenfors JJ, Gerhardson B, Hökeberg M Biological control of snow mould (Microdochium nivale) in winter cereals by Pseudomonas brassicacearum, MA250. BioControl. 2008;53:651-65.

17. Reva ON, Dixelius C, Meijer J, Priest FG. Taxonomic characterization and plant colonizing abilities of some bacteria related to Bacillus amyloliquefaciens and Bacillus subtilis. FEMS Microbiol Ecol. 2004;48:249-59.

18. Niazi A, Manzoor S, Asari S, Bejai S, Meijer J, Bongcam-Rudloff E. Genome analysis of Bacillus amyloliquefaciens Subsp. plantarum UCMB5113: a rhizobacterium that improves plant growth and stress management. PLoS One. 2014;9:e104651.

19. Knudsen IMB. Biological control of seedborne diseases in cereals [3 manuscripts included]. 1994. http://agris.fao.org/agris-search/search. do? recordID=DK9620600. Accessed 13 Nov 2017.

20. Kandler O, Stetter K-O, Köhl R. Lactobacillus reuteri sp. nov., a new species of Heterofermentative lactobacilli. Zentralblatt Für Bakteriol Abt Orig C Allg Angew Ökol Mikrobiol. 1980;1:264-9.

21. Díaz Herrera S, Grossi C, Zawoznik M, Groppa MD. Wheat seeds harbour bacterial endophytes with potential as plant growth promoters and biocontrol agents of fusarium graminearum. Microbiol Res. 2016;186-187: 37-43.

22. Shahzad R, Khan AL, Bilal S, Asaf S, Lee I-J. What is there in seeds? Vertically transmitted endophytic resources for sustainable improvement in plant growth. Front Plant Sci. 2018;9. https://doi.org/10.3389/fpls.2018.00024.

23. Le Cocq K, Gurr SJ, Hirsch PR, Mauchline TH. Exploitation of endophytes for sustainable agricultural intensification. Mol Plant Pathol. 2016;18:469-73.

24. Hubbard M, Germida JJ, Vujanovic V. Fungal endophytes enhance wheat heat and drought tolerance in terms of grain yield and second-generation seed viability. J Appl Microbiol. 2013;116:109-22.

25. Vlamakis $H$, Chai $Y$, Beauregard P, Losick R, Kolter R. Sticking together: building a biofilm the Bacillus subtilis way. Nat Rev Microbiol. 2013;11:157-68.

26. Kerstens M, Boulet G, Kerckhoven MV, Clais S, Lanckacker E, Delputte P, et al A flow cytometric approach to quantify biofilms. Folia Microbiol (Praha). 2015:60:335-42

27. Said J, Walker M, Parsons D, Stapleton P, Beezer AE, Gaisford S. Development of a flow system for studying biofilm formation on medical devices with microcalorimetry. Methods. 2015;76:35-40.

28. Ferreira IS, Kikhney J, Kursawe L, Kasper S, Gonçalves LMD, Trampuz A, et al. Encapsulation in Polymeric Microparticles Improves Daptomycin Activity Against Mature Staphylococci Biofilms-a Thermal and Imaging Study. AAPS PharmSciTech. 2018:1-12.

29. Butini ME, Cabric S, Trampuz A, Di Luca M. In vitro anti-biofilm activity of a biphasic gentamicin-loaded calcium sulfate/hydroxyapatite bone graft substitute. Colloids Surf B Biointerfaces. 2018;161:252-60.

30. Gonzalez Moreno M, Trampuz A, Di Luca M. Synergistic antibiotic activity against planktonic and biofilm-embedded Streptococcus agalactiae, Streptococcus pyogenes and Streptococcus oralis. J Antimicrob Chemother. 2017;72:3085-92.

31. Danielsson J, Reva O, Meijer J. Protection of oilseed rape (Brassica napus) toward fungal pathogens by strains of plant-associated Bacillus amyloliquefaciens. Microb Ecol. 2007:54:134-40.

32. NEWMEYER D. Filtering small quantities of conidial suspensions to remove mycelial fragments. Fungal Genet Rep 1990;37. doi:https://doi.org/10.4148/ 1941-4765.1480.

33. Holmberg A-IJ, Melin P, Levenfors JP, Sundh I. Development and evaluation of SCAR markers for a Pseudomonas brassicacearum strain used in biological control of snow mould. Biol Control. 2009;48:181-7.

34. Jiang H, Dong H, Zhang G, Yu B, Chapman LR, Fields MW. Microbial diversity in water and sediment of Lake Chaka, an Athalassohaline Lake in northwestern China. Appl Environ Microbiol. 2006;72:3832-45. 